\title{
Rhinostomies: an open and shut case?
}

\author{
Chris J McLean, Ian A Cree, Geoffrey E Rose
}

Moorfields Eye

Hospital, London EC1V 2PD

C J McLean

G E Rose

Institute of

Ophthalmology,

London EC1 9EL

I A Cree

Correspondence to: Mr G E Rose, Adnexal Unit, Moorfields Eye Hospital, City Road, London EC1V 2PD

Accepted for publication 12 July 1999

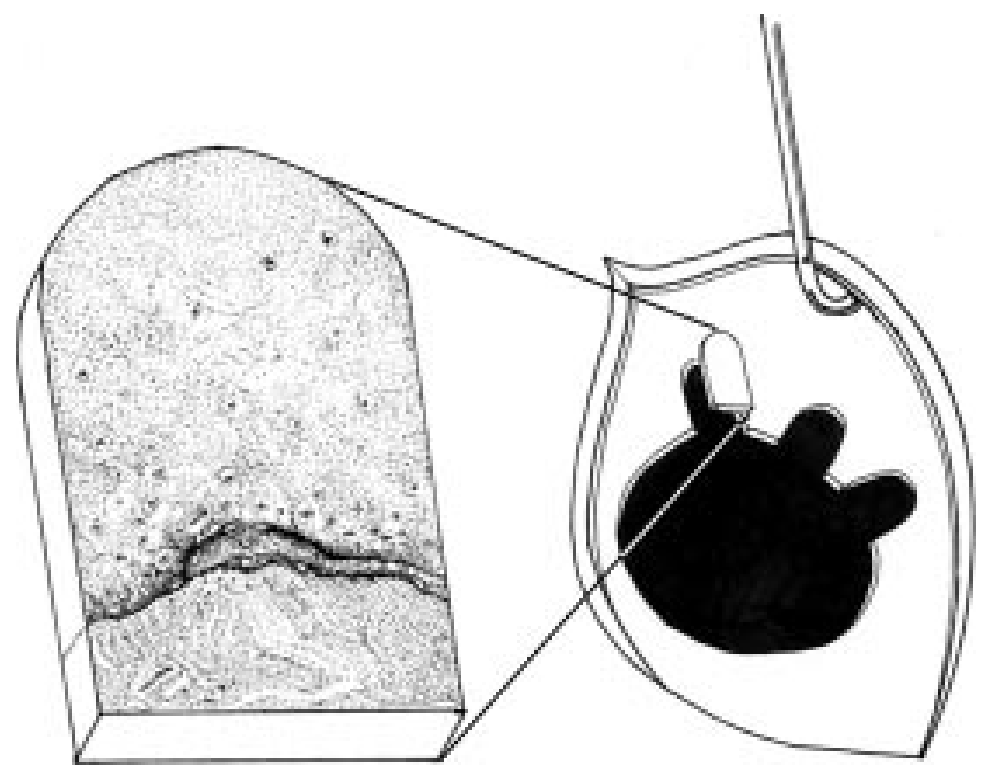

Figure 1 Diagram illustrating the removal of a bullet-shaped piece of bone from a rhinostomy and a close up view of the bone illustrating the small area of new bone formation. The orientation of the bone fragments was kept constant, relative to the edge of the rhinostomy, by engaging the jaws of the bone punch in a line perpendicular to the rhinostomy.

\begin{abstract}
Aims-To analyse bone fragments from rhinostomies of patients undergoing revisional dacryocystorhinostomy, looking for evidence of new bone formation.

Methods-14 consecutive patients undergoing secondary lacrimal surgery were included in this study. In each case the existing rhinostomy was enlarged with bone punches, care being taken to use the punches with the jaws cutting perpendicularly to the edge of the rhinostomy, to allow accurate orientation of the specimens. The fragments were examined histologically for evidence of new bone formation.

Results-Histological sections showed fragments of bone with variable fibrosis at the edge of the rhinostomy. There was evidence of only very little new bone formation.

Conclusion-This study has clearly shown that, at the edge of a rhinostomy, healing is predominantly by fibrosis and there is only very limited new bone formation. (Br F Ophthalmol 1999;83:1300-1301)
\end{abstract}

Dacryocystorhinostomy is a successful operation with a failure rate of less than $10 \%$ in most series $^{1-5}$ and the two most common causes for failure are a common canalicular obstruction and an inappropriate size or location of the osteotomy. ${ }^{67}$ In some cases the osteotomy is closed by granulation tissue $e^{2-4} 78$ and in others closure of the osteotomy has been attributed to new bone formation. ${ }^{267910}$

It has been the impression of the authors that remodelling of the edge of a rhinostomy is not marked, in that the scalloping of the bone edge by previously used bone punches is still visible at the time of revisional surgery. Fragments of bone from osteotomies in patients undergoing revisional dacryocystorhinostomy were examined histologically for evidence of new bone formation.

\section{Methods}

Fourteen consecutive patients (six male), referred following failed previous lacrimal surgery, were included in this prospective study, the average age at reoperation being 62 years (median 60; range 52-71). The median time from the original surgery to the repeated operation was 35 months (range 9-108 months).

All patients had been assessed in the lacrimal clinic at Moorfields with probing, syringing, and dye testing and three patients had dacryocystography. All revisional surgery was performed under general anaesthesia by one surgeon (GER), the surgical technique involving an external approach through the previous surgical scar. The orbicularis and angular vein were retracted using a squint hook and the periosteum mobilised from around the previous osteotomy site. The osteotomy was inspected and scar tissue dissected away, and in all cases the osteotomy was found to be small. Further fragments of bone were removed with Citelli bone punches, the punches being aligned perpendicularly to the edge of the osteotomy to allow the characteristically "bulletshaped" fragments of bone to be correctly orientated when examined later (Fig 1). The mucosal anastamosis was then extensively refashioned and the incision closed in layers.

The bone fragments were fixed in 10\% formol-saline, decalcified and stained with haematoxylin and eosin. The fragments were examined along a line of section perpendicularly to the edge of the previous rhinostomy, looking especially for any evidence of new bone formation.

\section{Results}

Forty eight bone fragments were examined from 14 patients, with an average of three fragments per patient. In all cases there was variable fibrosis at the edge of the rhinostomy (Fig 2). Some very limited new bone formation was present in $10(71 \%)$ patients. 


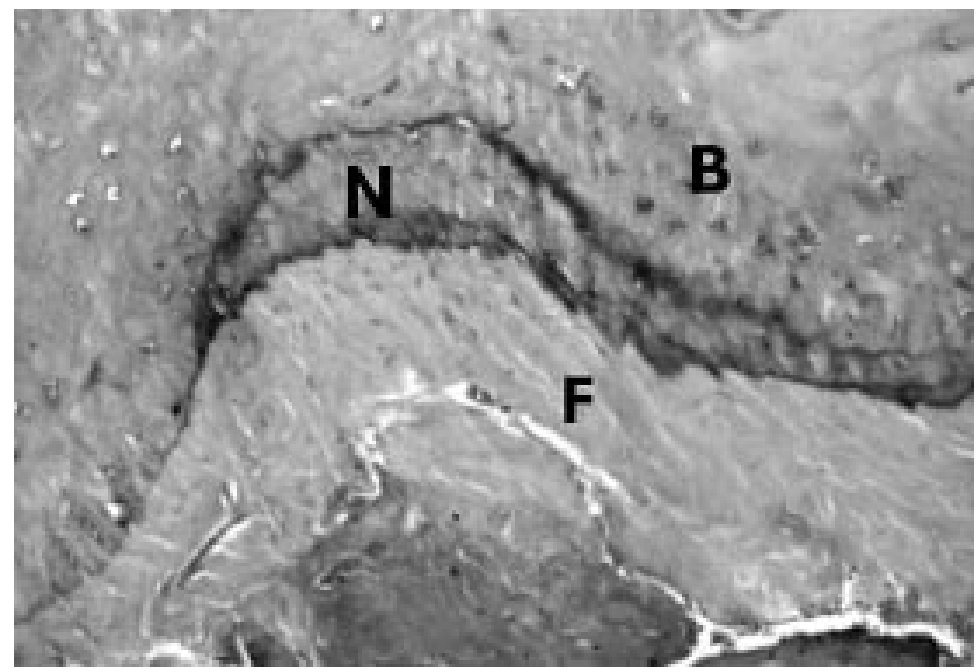

Figure 2 Histological section of a bone fragment showing normal nasal bone (B), a thin area of new bone formation $(N)$, and a large area of surrounding fibrosis $(F)$. Haematoxylin and eosin staining $(\times 200)$.

\section{Discussion}

The principle of external dacryocystorhinostomy has varied little since Dupuy-Dutemps and Bourguet described their modification of Toti's operation in 1921 and the commonest causes for failure are inappropriate size or location of the osteotomy and common canalicular obstruction. In some cases bone regrowth has been blamed for the failure of the primary surgery.

Welham and Wulc ${ }^{7}$ described 19 patients, from a series of 204 undergoing secondary dacryocystorhinostomy, who had no bony ostium at the time of secondary surgery. They commented that a higher percentage of children $(24 \%)$ were seen to have reformed ostia at the time of secondary surgery compared with adults $(6 \%)$ and proposed that this might be due to more rapid bone growth in children. However, they also drew attention to the point that if a mucosal edge to edge anastamosis had been performed at the primary operation, then it was highly unlikely that bony regrowth would proceed across such an established tissue plane.

McLachlan et $a l^{6}{ }^{6}$ in a series of 291 repeat dacryocystorhinostomies, found that the osteotomy was closed in four patients. In three this was due to granulation tissue and in one patient it was due to new bone growth. Glatt et $a l^{9}$ examined five failed dacryocystorhinostomies using computed tomographic dacryocystography: in one patient bilateral bone regrowth had apparently developed which separated the lacrimal sacs from the nasal cavity, this being confirmed at secondary surgery. The surgeon who had performed the original surgery stated that he had removed the entire bony wall of each lacrimal sac fossa in a patient with bilateral disease. Iliff $^{2}$ reported the results of his dacryocystorhinostomy technique on 87 patients, with a success rate of $90 \%$. He used a Stryker saw with a trephine attachment which cleanly cut out a $10 \mathrm{~mm}$ diameter piece of bone. In this series there was one patient who had an unsuccessful dacryocystorhinostomy due to closure of the osteotomy, for which the author had no explanation.

Our study analysed bone fragments from dacryocystorhinostomies in 14 patients and all fragments were removed by the same surgeon in a reproducible manner. The results were the same in all cases, with variable fibrosis at the edge of the rhinostomy but almost no new bone formation. Welham and Wulc ${ }^{7}$ suggested that reformed ostia are seen more commonly in children, although the present study does not include children. In the adult population, it would be surprising if bone regrowth was an "all or nothing" phenomenon and, consequently, evidence of marked new bone formation would be expected in all patients undergoing secondary surgery if it were truly a common and significant phenomenon during healing. Our results failed to substantiate this and cast doubt as to whether there is significant growth of new bone during the healing of primary open lacrimal surgery.

As a general principle new bone formation requires the presence of periosteum and, in patients undergoing dacryocystorhinostomy, the periosteum is stripped away, thereby possibly frustrating new bone formation. We, as others, ${ }^{7}$ believe it probable that significant new bone formation will not occur where there has been adequate mucosal anastomosis at the time of the original surgery and in practical terms, primary epithelial closure almost certainly inhibits the new bone formation otherwise likely to occur with secondary intention healing.

1 McPherson SD Jr, Egleston D. Dacryocystorhinostomy: a review of 106 operations. Am f Ophthalmol 1959;47:32831.

2 Iliff CE. A simplified dacryocystorhinostomy. Arch Ophthalmol 1971;85:586-91.

3 Welham RAN, Henderson PH. Results of dacryocystorhinostomy: analysis of causes for failure. Trans Ophthalmol Soc UK 1973;93:601-9.

4 Pico G. A modified technique of external dacryocystorhinostomy. Am f Ophthalmol 1971;72:679-90.

5 Romanes GJ. Dacryocystorhinostomy: clinical report of fifty cases. Br f Ophthalmol 1955;39:237-40.

6 McLachlan DL, Shannon GM, Flanagan JC. Results of dacryocystorhinostomy: analysis of the reoperations. Ophthalmic Surg 1980;11:427-30.

7 Welham RAN, Wulc A. Management of unsuccessful lacrimal surgery. Br F Ophthalmol 1987;71:152-7.

8 Kao SCS, Liao CL, Tseng JHS, et al. Dacryocystorhinostomy with intraoperative mitomycin C. Ophthalmology 1997; 104:86-91.

9 Glatt HJ, Chan AC, Barrett L. Evaluation of dacryocystorhinostomy failure with computed tomography and computed tomographic dacryocystography. Am $\mathcal{F}$ Ophthalmol 1991; 112:431-6.

10 Rob and Smith's operative surgery. 4th ed. London: Butterworths, 1984; vol VI:60. 